\title{
Experimen Data Cuaca BMKG untuk Memprediksi Potensi Energi Alternativ Tenaga Angin di Kota Bandar Lampung
}

\author{
Achmad Aries Pirnando*1, Bayu Megantoro ${ }^{2}$, Fitri Andriyani ${ }^{3}$ \\ 1,2,3 Magister Teknik Informatika, Perguruan Tinggi Raharja \\ E-mail: *1achmad.ariespirnando@gmail.com, 2bymegantoro@gmail.com, \\ ${ }^{3}$ fitri.andriyani@raharja.info
}

\begin{abstract}
Abstrak
Energi merupakan kebutuhan primer dalam kehidupan manusia terutama di kota Bandarlampung. Salah satu energi tersebut yaitu energi angin. Untuk mengetahui potensi angin di kota Bandarlampung maka dilakukan experiman data cuaca yang didapat dari BMKG. Data tersebut dianalisis menggunakan teknik datamining prediksi dengan menggunakan algoritma MLP atau multilayer perceptron. Berdasarkan hasil prediksi yang didapatkan, kecepatan angin rata-rata untuk untuk enam tahun kedepan mengalami penuruan, penurunan kecepatan angin tersebut tidak cukup signifikan melainkan berkisar kurang lebih enam knot.
\end{abstract}

Kata Kunci : Experimen, Prediksi, Cuaca

\begin{abstract}
Energy is a primary need in human life, especially in the city of Bandarlampung. One such energy is wind energy. To know the potential of wind in the city bandarlampung then experiman weather data obtained from BMKG. The data were analyzed using predictive datamining technique using MLP or multilayer perceptron algorithm. Based on the predicted results obtained, the average wind speed for the next six years has decreased, the decrease in wind speed is not significant enough but ranges from approximately six knots.
\end{abstract}

Keywords : Experiment, Prediction, Weather

\section{Pendahuluan}

Energi merupakan kebutuhan primer dalam kehidupan manusia modern. Hampir semua aspek kehidupan memerlukan energi sebagai penggerak utama, Meningkatnya permintaan energi di Kota Bandar Lampung saat ini tidak seimbang dengan ketersediaan suplai energi. Fenomena padamnya listrik di wilayah Kota Bandar Lampung merupakan pertanda bahwa pasokan energi di tengah masyarakat mulai menurun, hal ini mengakibatkan Pemkot (Pemerintah Kota) Bandar lampung harus mencari energi listrik alternativ untuk menyuplai kebutuhan masyarakat. Sumber energi tenaga angin merupakan salah satu energi alternativ yang ramah lingkungan dan dapat dimanfaatkan oleh Pemkot Bandar lampung.

Berdasarakan penelitian terhadap pembangkit listrik tenaga angin, kecepatan laju angin di suatu daerah sangat mempengaruhi energi yang dihasilkan[1]. Pembangunan sumber energi listrik tenaga angin dikota Bandar lampung harus melalui studi kelayakan terhadap faktor iklim dan kecepatan angin untuk mengetahui potensi yang ada.

Pengolahan data informasi iklim di BMKG merupakan salah satu solusi untuk menentukan kelayakan iklim dalam memabangun sumber energi alternativ tenaga angin di 
provinsi lampung. Berdasarkan data yang didapatkan dari BMKG terdapat beberapa parameter seperti suhu, curah hujan, dan kecepatan angina.

Ketersediaan data dalam jumlah yang besar mampu memberikan informasi penting namun sulit terlihat secara kasat mata. Untuk hal tersebut, maka pendekatan data mining sebagai bidang komputasi yang mampu menggali informasi penting pada data yang besar harus dilakukan. Data mining adalah serangkaian proses untuk menggali nilai tambah dari suatu kumpulan data berupa pengetahuan yang selama ini tidak diketahui[2]. Berdaasarkan hal tersebut maka pada penelitian ini dilakukan upaya eksperimen terhadap data Iklim BMKG dengan menggunakan teknik data mining, yang bertujuan untuk menemukan informasi yang cocok sebagai salah satu faktor pendukung untuk membangun sumber energi listrik tenaga angin di kota Bandar lampung.

\section{Metode Penelitian}

Data mining adalah penerapan algoritma tertentu untuk mengekstrak pola dari data[3].Beberapa metode data mining yang umumnya menggunakan teknik machine learning, pengenalan pola dan statistik menurut Fayyad [3] diantaranya klasifikasi, klasterisasi, regresi(prediksi) dan sebagainya. Penggunaan masing-masing metode bergantung pada jenis data dan bentuk informasi yang ingin diketahui. Untuk data yang umumnya tidak memiliki label atau target kelas, beberapa metode data mining yang bisa digunakan yaitu prediksi dan klasterisasi.

\subsection{Prediksi dengan Multilayer Perceptron (MLP)}

Prediksi atau biasa disebut forecasting merupakan metode data mining yang bertujuan memperkirakan nilai dari atribut tertentu pada masa yang akan datang dengan memperhatikan data sebelumnya yang bersifat time series (berdasarkan waktu). Kajian mengenai forecasting pada data mining sudah pernah dilakukan, dan salah satu pendekatan yang banyak digunakan menggunakan algoritma Multilayer Perceptron (MLP)[4,5,6,7]. Algoritma MLP merupakan variasi dari Artificial Neural Network (ANN) dengan kelebihan yang mendukung proses forecasting seperti bersifat umum dan fleksibel serta robust terhadap data yang bersifat nonlinier dengan distribusi yang tidak normal[6].

MLP merupakan varian ANN dengan karakteristik memiliki minimal tiga layer yang meliputi input layer, hidden layer (bisa lebih dari satu) dan output layer[8].Penggunaan topologi jaringan berlapis ini memungkinkan algoritma untuk menyerap pola data lebih dalam melalui pembobotan neuron-neuron nya.

\subsection{Data dan Tools Penelitian}

- Data Iklim didapatkan dari portal data BMKG Indonesia provinsi Lampung (http://dataonline.bmkg.go.id), dari Stasiun Meteorologi Maritim Lampung (Bandar Lampung).

- Data yang dikumpulkan dari tahun 2010 sampai dengan 2017.

- Digunakan tool pendukung WEKA (Waikato Environtment for Knowledge Analysis).

\subsection{Desain Tahap Penelitian}

Pada desain eksperimen ini, tahap integrasi, tahap seleksi data dan pembersihan data dilakukan untuk membantu memudahkan proses pengalian data pada fase berikutnya yaitu prediksi dan kesimpulan. Berikut secara rinci tahap eksperimen yang dilakukan: 


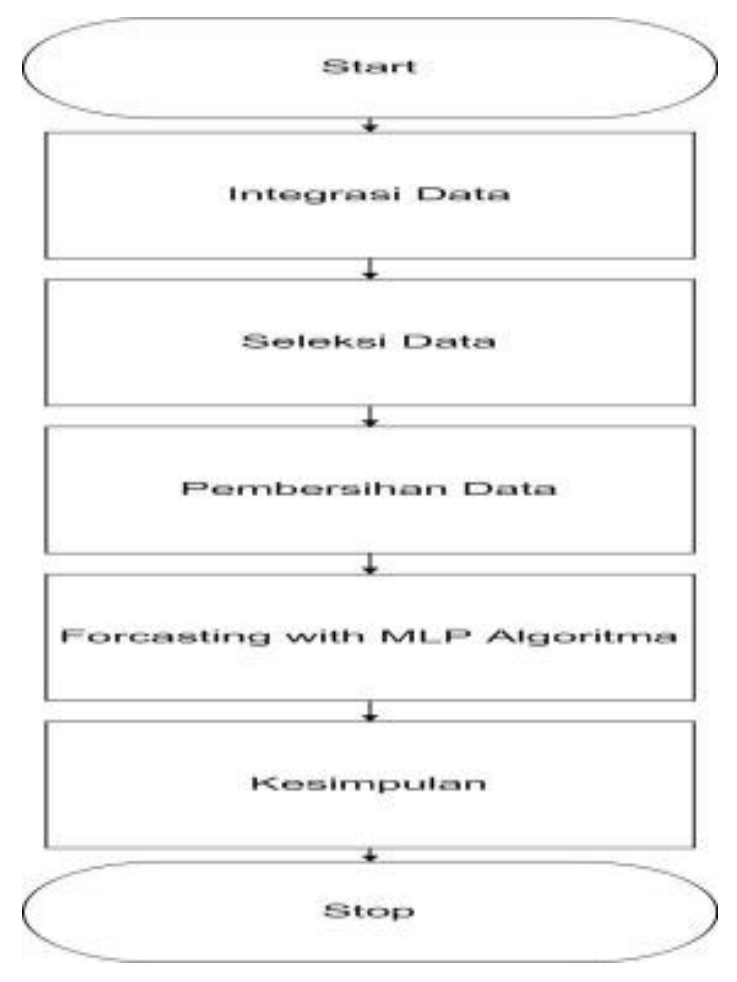

Gambar I Tahap Penelitian

1. Integrasi Data

Data didapatkan dari Portal data BMKG Indonesia dengan total data 2649 instance, data tersebut terdiri dari atribut : Nama Stasiun, WMO Id, Tanggal, Suhu Minimum, Suhu Maksimum, Suhu Rata-Rata, Kelembaban Rata-Rata, Curah Hujan, Lama Penyinaran, Kecepatan Angin Rata-rata, Arah angin terbanyak, kecepatan angin terbesar, Arah Angin Saat kecepatan Maksimal.

\section{Seleksi Data}

Pada tahap seleksi data dilakukan beberapa aksi seperti berikut:

- Atribut yang digunakan untuk penelitian dalam prediksi yaitu, Angin Rata-rata, dan Tanggal.

3. Pembersihan Data

Data yang didapatkan juga mengandung missing value (bukan nol) yang kemudian jika data tersebut terjadi diawal-awal tahun maka diubah menjadi 0 , dengan asumsi belum ada atau belum terdata (*9999). Sedangkan jika missing terjadi diantara tahun yang memiliki nilai, diberikan nilai rata-rata dari data pada atribut yang sama $(* 8888)$.

4. Forcasting Data

Setelah data dibersihkan, dilakukan proses mining dengan menggunakan teknik forcasting. Teknik Forcasting ini dilakukan untuk mengetahui prediksi di kemudian hari mengenai data yang dihasilkan. Hasil dari forcasting ini berupa prediksi bulanan dan tahunan data angin rata-rata.

5. Kesimpulan 
Setelah melakukan proses mining, maka akan diketahui hasil atau kesimpulan tertentu. Kesimpulan ini didapatkan dari stasiun BKMG atau daerah mana yang cocok untuk dan memiliki potensi besar untuk diterapkan dalam membangun pembangkit energi tenaga listrik.

\section{Hasil dan Pembahasan}

Implementasi data cuaca BMKG dilakukan dengan cara forcasting. Forcasting ini dilakukan dengan parameter hasil yaitu prediksi 10Tahun. Proses ini dilakukan setelah pembersihan data dan proses forcasting menggunakan tools weka (Waikato Environment for Knowledge Analysis). Berikut merupakan hasil forcasting yang telah dilakukan.

\subsection{Hasil Forcasting}

Berikut merupakan table hasil forcasting yang dilakukan dengan menggunakan tools weka dengan hasil prediksi untuk enam tahun kedepan.

Tabel 1. Data forcasting Kecepatan angin rata-rata (prediksi)

\begin{tabular}{|c|c|}
\hline Tahun & Kecepatan Angin Rata-rata (Prediksi) \\
\hline 2018 & 6.1033 \\
\hline 2019 & 5.9696 \\
\hline 2020 & 5.7833 \\
\hline 2021 & 5.6763 \\
\hline 2022 & 5.6399 \\
\hline 2023 & 5.6262 \\
\hline
\end{tabular}




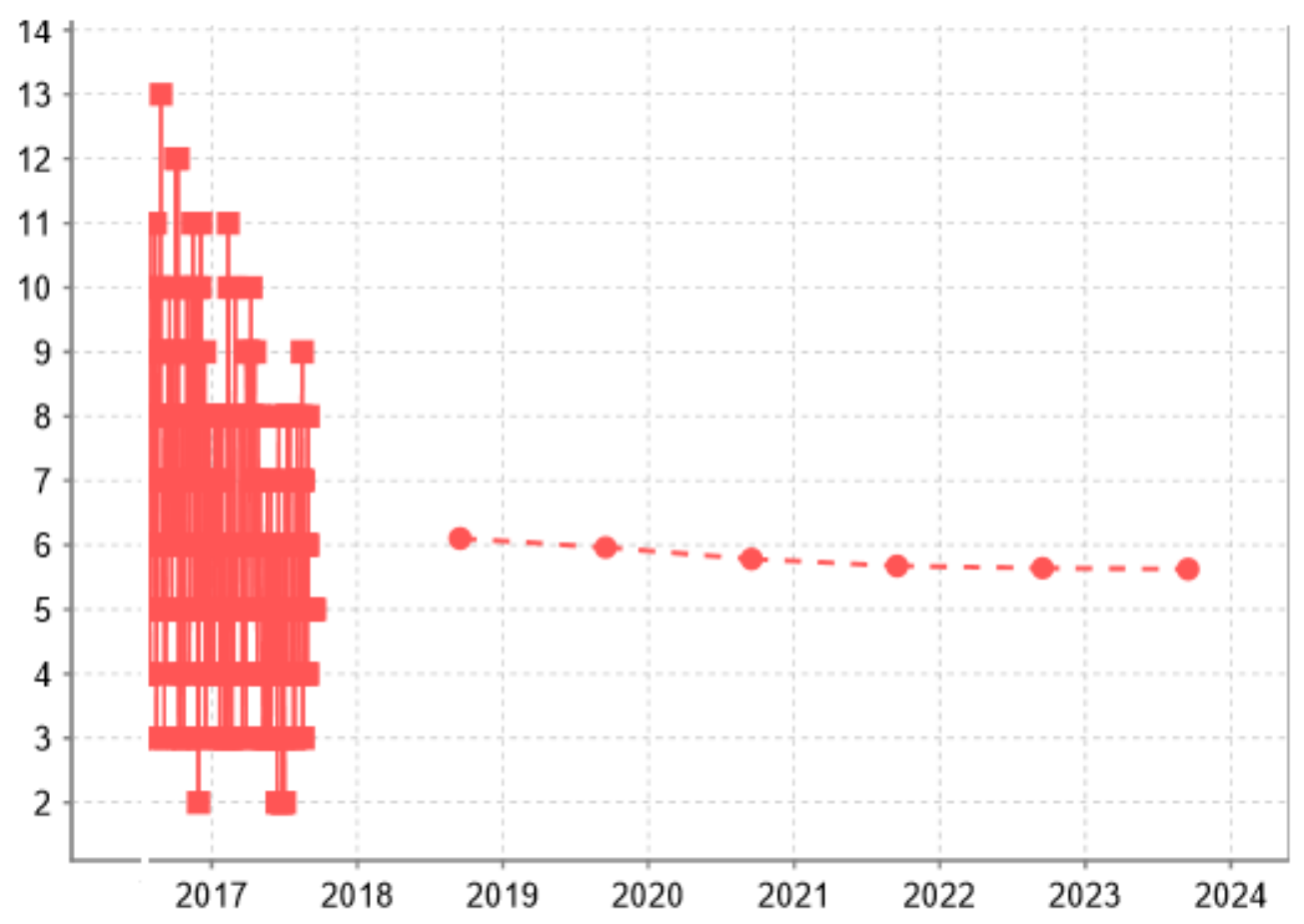

Gambar 2. Grafik Forcasting Tahunan

\subsection{Analisis}

Berdasarkan hasil forcasting atau prediksi bulanan dan harian, maka didapatkan penjelasan bahwa :

1. Hasil prediksi tahunan, didapat kecepatan angin rata-rata tertinggi sebesesar \pm 6 Knot dan terendah $\pm 5 \mathrm{knot}$, dari grafik diatas atau forcasting Tahunan dapat diambil kesimpulan bahwa terjadi penurunan kecepatan angsin rata-rata setiap tahunya

\section{Kesimpulan}

Berdasarkan uraian yang telah dijelaskan, bahwa experimen terhadap data cuaca BMKG dapat diambil keputusan.

1. Kecepatan angin diprediksi setiap tahunya akan mengalami penurunan walaupun tidak terlalu signifikan.

2. Berdasarkan data yang didapat, data penurunan kecepatan angin rata-rata di kota bandarlampung berkisar antara $\pm 5 \mathrm{Knot}$

\section{Saran}

Experimen data cuaca BMKG untuk prediksi tenaga angin ini hanya menggunakan 2 parameter saja yaitu tanggal didapatkan data dan nilai dari data kecepatan angin rata-rata saja, diharapkan untuk penelitian selanjutnya dapat melakukan experimen dengan parameter yang lebih banyak agar hasil informasi yang akan didapatkan dari data tersebut cukup besar. 


\section{DAFTAR PUSTAKA}

[1] Hardiantono, Damis \& Sumbung, F, H (2012). Visibilitas Penempatan Pembangkit Listrik Tenaga Angin Di Pantai Payum Merauke. Jurnal Ilmiah Mustek ANIM, 20896697.

[2] Dunham, M.H. 2003. Data mining Introductory and advanced topic. New Jersey : Prentice Hall

[3] Fayyad, Usama dkk., From Data Mining to Knowledge Discovery in Databases, AI Magazine Vol. 17, 1966

[4] Khan, Muhammad Riaz., Short Term Load Forecasting with Multilayer Perceptron and Recurrent Neural Network. Journal of Electrical Engineering Vol 53 No.1-2, 2002.

[5] Meinanda, Muhammad Hanief., Prediksi Masa Studi Sarjana dengan Artificial Neural Network, Internetworking Indonesia Journal Vol. 1 No.2, 2009.

[6] Moreno, Juan Jose Montano dkk., Artificial Neural Networks Applied to Forecasting Time Series, Psicothema Vol.23 No. 2 pp.322-329, 2011.

[7] Nemes, Magdalena Daniela and Butoi, Alexandru., Data Mining on Romanian Stock Market Using Neural Network for Price Prediction, Informatica Economica Vol. 17 No. 3, 2013.

[8] Hornik, Kur., Multilayer Feedforward Networks are Universal Approximators, Neural Networks, Vol. 2 pp.359-366,1989. 